\title{
Predictive Current Control of an Active Harmonic Filter
}

\author{
Chris Townsend $^{\dagger 1}$, Christopher Rowe ${ }^{\dagger 2}$, Terrence Summers ${ }^{\dagger 3}$ and Tim Wylie ${ }^{\ddagger}$ \\ ${ }^{\dagger}$ School of Electrical Engineering and Computer Science \\ University of Newcastle, Callaghan, NSW, Australia, 2308. \\ Email: ${ }^{1}$ Chris.Townsendestudentmail.newcastle.edu.au, \\ ${ }^{2}$ Christopher.Rowelstudentmail.newcastle.edu.au \\ ${ }^{3}$ Terry. Summers a newcastle.edu. au \\ ${ }^{\ddagger}$ ResTech Pty. Ltd. \\ University of Newcastle, Callaghan, NSW, Australia, 2308. \\ Email: twyliedrestech. net.au
}

\begin{abstract}
Voltage and current harmonics can have various deleterious effects on the entire power system, from residential households to power utilities. The onus to correct these harmonic problems lies dually with the end user and the power utilities. Active Harmonic Filters are one solution that can ensure the supply of clean power, to end users in a distributed system. Research into active harmonic filters has become an area of growing interest in the recent years. This is due to the increased use of non-linear loads, coupled with greater demand for electricity in general. This paper outlines the development of simulations and low voltage modeling of a pure active harmonic filter. The filter is composed of a three phase inverter direct-connected in shunt with the load and a microcontroller used to implement the control strategy. The control algorithm and filtering are performed in the dq rotating reference frame. This implementation attempts to improve the control scheme proposed by Akagi et. al for "Pure Active Harmonic Filters." The output stages of the control scheme are replaced with a predictive current controller with space vector modulation. Simulation and experimental results are provided to support the findings of this paper.
\end{abstract}

Index Terms-Pure active filters, diode rectifiers, harmonic compensation, predictive current control, deadbeat current control.

\section{INTRODUCTION}

V ARIATION in shunt Active Harmonic Filters (AHFs) predominantly occurs in the control strategy implementation. Most techniques measure the load and/or supply current, the controller then operates on the part of the frequency spectrum associated with harmonic currents. The author of [1] details a relatively simple strategy where the fundamental frequency is filtered out in the rotating dq frame. The remaining harmonic currents are then fed into what is essentially a proportional controller which supplies three single phase triangular wave PWM controllers. In [2], Blaabjerg describes a more complex implementation where specific harmonic currents are isolated in each rotating harmonic reference frame, a separate PI controller is then designed for each harmonic. The method described in [2] results in a lower THD value at the expense of computational power. Both strategies however have poor performance for transient suppression of harmonics due to the delay in the P and PI loops. This paper presents an improvement to the afore mentioned schemes by implementing a dead-beat current controller and a Space Vector Modulation (SVM) scheme. The controller takes, as an input the sum of the required harmonics to be injected, and applies a switching pattern to the inverter based on software routines which infer the average required voltage to produce the demanded current. The proposed control strategy filters the fundamental component in the rotating fundamental frame and then uses the SVM based predictive current controller to produce the required harmonic canceling currents. This paper outlines the development and results of simulations and the low voltage modeling of a pure active harmonic filter; implementing this new control scheme.

\section{EXISTING CONTROL}

In the general case of an AHF, the device consists of a combination of a control system and an inverter. The inverter is controlled to produce harmonic currents or voltages to cancel out harmonics at the Point of Common Coupling (PCC). The control scheme for a Pure AHF discussed in [1], [3] and [4] is composed of feedback control, feed forward control and a phase locked loop (PLL). Fig. 1 shows the control system in its entirety. The filter is composed of a three phase inverter directconnected in shunt with the load with a microcontroller used to drive the MOSFET firing signals. This Pure AHF does not utilise passive filtering. Fig. 2 shows the configuration of the Pure AHF and its connection to the grid. Table I summarises the system parameters, for this project, and their respective values.

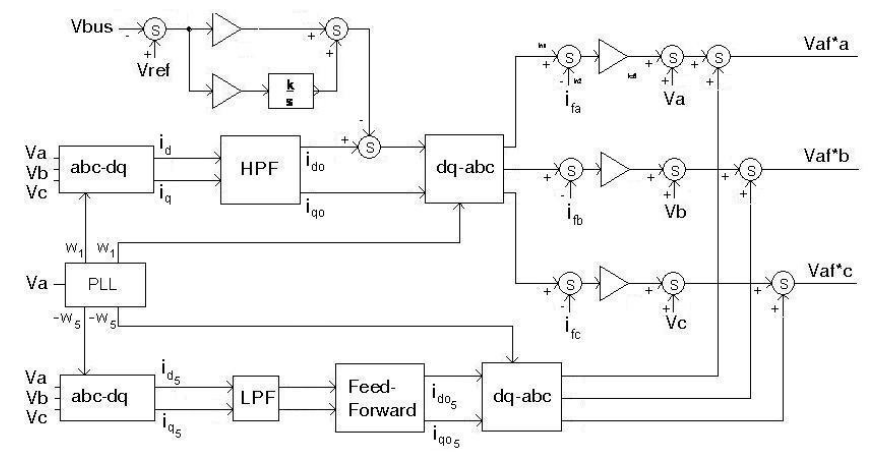

Figure 1. Rotating Fundamental Frame Control Scheme

The control scheme from [1] utilises a rotating reference frame to simplify the calculations required, and thus increase 


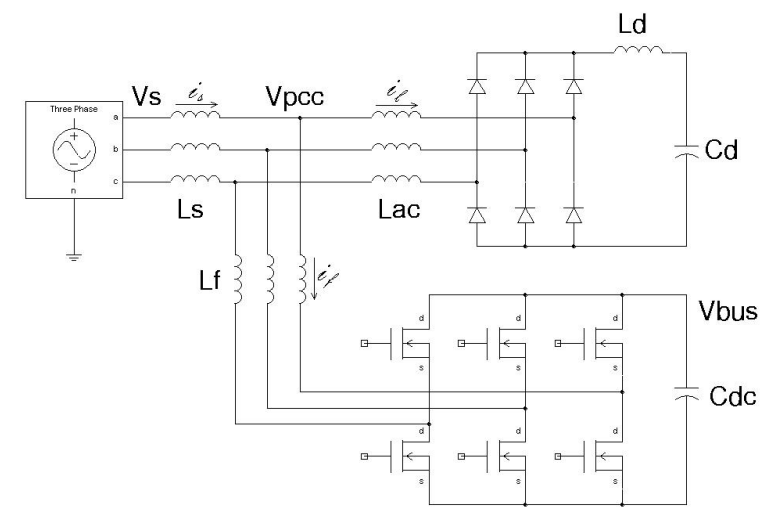

Figure 2. Hardware Configuration

Table I

SPeCificAtions AND PARAMETERS OF THE System

\begin{tabular}{|c|c|}
\hline Component & Value \\
\hline \hline Nominal line-to-line rms voltage $\left(V_{l-l}\right)$ & $20 \mathrm{~V}$ \\
\hline Line frequency $\left(f_{s}\right)$ & $50 \mathrm{~Hz}$ \\
\hline Source inductance $\left(L_{s}\right)$ & $0.1 \mathrm{mH}$ \\
\hline AC inductor $\left(L_{a c}\right)$ & $1 \mathrm{mH}$ \\
\hline DC inductor $\left(L_{d}\right)$ & $2 \mathrm{mH}$ \\
\hline DC capacitor $\left(C_{d}\right)$ & $2.2 \mathrm{mF}$ \\
\hline DC voltage of the rectifier & $21 \mathrm{~V}$ \\
\hline Three phase rectifier rating & $30 \mathrm{~W}$ \\
\hline Filter inductor $\left(L_{f}\right)$ & $2 \mathrm{mH}$ \\
\hline Filter DC bus capacitor $\left(C_{d c}\right)$ & $14.1 \mathrm{mF}$ \\
\hline DC voltage of the filter $\left(V_{b u s}\right)$ & $42 \mathrm{~V}$ \\
\hline Active filter rating $\left(P_{A F}\right)$ & $300 \mathrm{~W}$ \\
\hline
\end{tabular}

the frequency of control iterations achievable. In this case the rotating frames are related to the frequency of the voltages and currents seen in the network or in the control system as variables. In this implementation the rotating fundamental frame is shifted $50 \mathrm{~Hz}$ to the left in the spectrum. This allows a reduction in the complexity of the digital high pass filter.

To convert from the stationary abc frame to this rotating dq frame, the Park Transformation is used:

$\left[\begin{array}{l}i_{d} \\ i_{q}\end{array}\right]=\left[\begin{array}{ccc}\cos \theta & \cos \left(\theta-\frac{2 \pi}{3}\right) & \cos \left(\theta+\frac{2 \pi}{3}\right) \\ -\sin \theta & -\sin \left(\theta-\frac{2 \pi}{3}\right) & -\sin \left(\theta+\frac{2 \pi}{3}\right)\end{array}\right]\left[\begin{array}{c}i_{a} \\ i_{b} \\ i_{c}\end{array}\right]$

Note that this transformation is only valid when $i_{a}+i_{b}+i_{c}=$ 0 . If this is not the case the transformation does not transform a three coordinate reference frame to a two coordinate frame. As the project is aimed at compensating a three-wire network this condition is inherently true.

To reverse the conversion, from the dq frame to the abc frame, the Inverse Park Transform is used:

$$
\left[\begin{array}{c}
i_{a} \\
i_{b} \\
i_{c}
\end{array}\right]=\left[\begin{array}{cc}
\cos \theta & \sin \theta \\
\cos \left(\theta-\frac{2 \pi}{3}\right) & \sin \left(\theta-\frac{2 \pi}{3}\right) \\
\cos \left(\theta+\frac{2 \pi}{3}\right) & \sin \left(\theta+\frac{2 \pi}{3}\right)
\end{array}\right]\left[\begin{array}{c}
i_{d} \\
i_{q}
\end{array}\right]
$$

The abc-dq transform block, shown in Fig. 1, takes as inputs the three phase sampled supply currents, and the sine and cosine of the voltage angle $\theta$. A PLL is used to lock onto the supply frequency and hence produce the voltage angle $\theta$. The abc-dq block performs the Park Transform shown in (1). A High Pass Filter with a cut-off frequency of $16 \mathrm{~Hz}$ filters out the DC component of the spectrum; corresponding to the fundamental frequency of the supply. The dq-abc transform block performs the Inverse Park Transform shown in (2). The output of these three blocks is the spectrum of harmonic currents to be canceled. The K gain block effectively converts the required harmonic currents to be injected, into a voltage reference variable which is compared to a $10 \mathrm{kHz}$ triangle wave to provide firing signals to the inverter. The filter transfer function is given in (3).

$$
I_{s h}=\frac{Z_{f}}{K+s L_{s}+Z_{f}} I_{L h}
$$

Where $I_{s h}$ is the harmonic spectrum of the supply current and $I_{L h}$ is the harmonic spectrum of the load current.

The transfer function above indicates that by making $\mathrm{K}$ infinite we achieve perfect harmonic compensation. In reality the $\mathrm{K}$ value is limited by its impact on system stability.

DC bus voltage control is implemented by introducing a PI loop that subtracts from the lagging fundamental current $\left(\mathrm{i}_{d}\right)$. As real power is defined as:

$$
P=V I \cos \theta
$$

By controlling the lagging current we are essentially controlling the angle $\theta$, and hence controlling whether real power is flowing in or out of the inverter.

In this analysis we have neglected to mention the current and voltage summers placed, respectively, immediately before and after the $\mathrm{K}$ gain. The line voltages are added to the reference fed into the controller. This is done to cancel the fundamental voltage being placed across the filter inductor. Without the voltage summers the fundamental filter current will increase significantly. Adding the current summers to the Saber implementation of the control strategy provides stability to the DC bus control. The authors of [1] note that they are included to improve current controllability. It is clear that the presence of the current summers introduces negative feedback into the control of the currents.

The 5th harmonic feed-forward control variable is also included in the voltage summation, implemented after the $\mathrm{K}$ gain. This feed-forward control is added to improve the filter characteristic at the most dominant 5th harmonic frequency. This harmonic is dominant due to the three-phase diode rectifier load's spectrum. The feed-forward operates outside the proportional controller which is implemented via the $\mathrm{K}$ gain. This results in a faster filter response in the compensation of the 5 th harmonic.

Feed-forward control is also performed in a rotating frame of reference. However this time the frame is rotating at $250 \mathrm{~Hz}$. This ensures that when the Park Transform is performed the 5th harmonic is transformed to a DC signal which is isolated via the Low Pass Filter (LPF). The direction of rotation is negative due to the 5th harmonic being a purely negative sequence current. The output of the LPF is the current required to be injected via the inverter. To inject this current the inverter needs to apply an average voltage. This voltage is computed by multiplying the required current by the output filter inductor impedance, as in (5).

$$
v_{f}=z_{f} i_{f}
$$

The control strategy described thus far inherently has poor performance for transient suppression of harmonics due to the delay of the P and PI loops. The remainder of this paper 
presents a new implementation of the afore mentioned scheme by implementing a dead-beat current controller and a SVM scheme to replace the proportional controller and triangular wave PWM controllers.

\section{SySTEM CONFIGURATION}

Fig. 2 shows the experimental system consisting of; an inverter, microcontroller, voltage source and three phase diode rectifier. The $300 \mathrm{~W}$ voltage-source PWM inverter is direct connected to the PCC via line inductors. The inverter used is a pre-constructed Microchip MC1 Low Voltage Power Module. The DC bus within the module is rated to $48 \mathrm{~V} \mathrm{DC}$. Operating the voltage bus at $42 \mathrm{~V}$ is sufficient to provide harmonic compensation for a $20 V_{L L}$ RMS system; supplying a threephase diode rectifier load. The three-phase diode rectifier depicted in Fig. 2 is specially designed and constructed for the injection of fifth and seventh-harmonic currents. The inverter unit is controlled by the dsPIC30F Microchip Development board, with a processor speed of $29.14 \mathrm{MHz}$. This allows control algorithms for harmonic compensation to be executed at $10 \mathrm{kHz}$. Peripheral devices have been implemented on a separate PCB to provide feedback signals to the microcontroller.

The system shown in Fig. 2 provides an appropriate experimental system for the testing of control algorithms. The system parameters shown in Fig. 2 are given in Table I.

\section{NEW IMPLEMENTATION}

\section{A. Space Vector Modulation}

Space Vector Modulation is often used in AC machine control as a space vector physically represents the magnetic field density inside the machine. This concept can be utilised in the control of an inverter due to the close relationship between space vectors and temporal phasor voltages and currents produced by the inverter and associated loads.

The control theory discussed in Section II produces output variables in the abc coordinate reference frame, namely voltage reference signals. These three-phase voltage reference signals form a single voltage space vector which can be transformed into the $\alpha \beta$ stationary reference frame. This transformation from abc to $\alpha \beta$ is performed by the Clark Transform. Performing this transformation creates a one to one relationship between the control voltages in the $\alpha \beta$ frame and the two coordinate frame depicting the voltage vectors applied by an inverter.

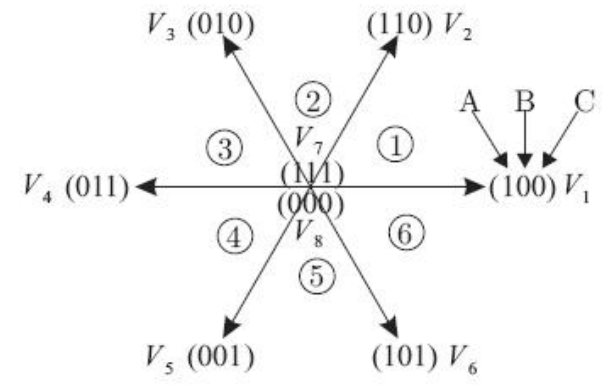

Figure 3. Voltage Vector Diagram

Fig. 3 shows the two coordinate frame and the six base voltage vectors which can be applied by a three-legged $\mathrm{H}$ Bridge inverter. The inverter can produce vectors in between the six base shown by applying a combination of the base

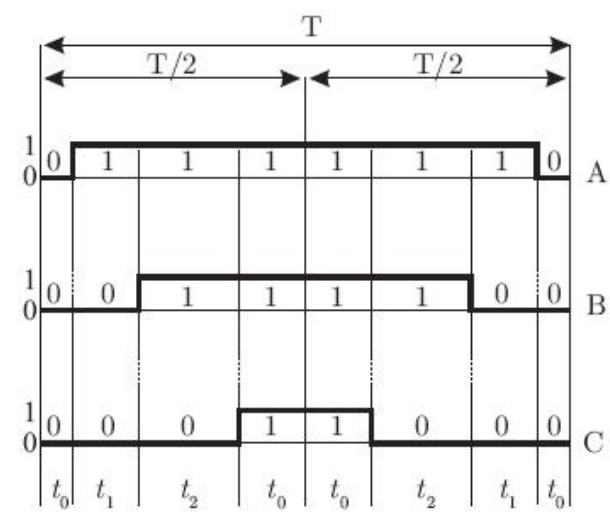

Figure 4. Switching Pattern for Sector 1 Voltages

vectors in any control period; this results in an average voltage vector of the desired sense and magnitude.

Fig. 4 depicts the switching pattern required to produce an average voltage vector in sector 1 of the two coordinate plane. There are simple linear algebraic relationships between the normalised orthogonal projections of the $\alpha \beta$ vector and the switching times $\mathrm{t}_{0}, \mathrm{t}_{1}$ and $\mathrm{t}_{2}$. These switching times can be calculated by performing a Clark transform on the output control voltages and subsequently applying linear algebra and SVM. This can form the basis of an effective and computationally efficient controller.

\section{B. Deadbeat Current Controller}

This paper builds on the control scheme proposed in [1], [3]. The new implementation removes the output stages of the control scheme; the proportional controller and three single phase triangle wave PWM controllers. The output stage is replaced with a predictive current controller [5] based in the $\alpha \beta$ frame and an SVM generator. Fig. 5 shows the new implementation. The implemented current controller draws on the close relationship between space vectors and the temporal phasor voltages of an inverter. Conversion from the dq rotating frame to the stationary $\alpha \beta$ frame allows the subsequent calculation of SVM duty cycle. This duty cycle calculation samples the voltage at the PCC and is able to produce a desired average current by the end of each control period. Thus a change in control will occur as a response to a variance in load within one cycle.

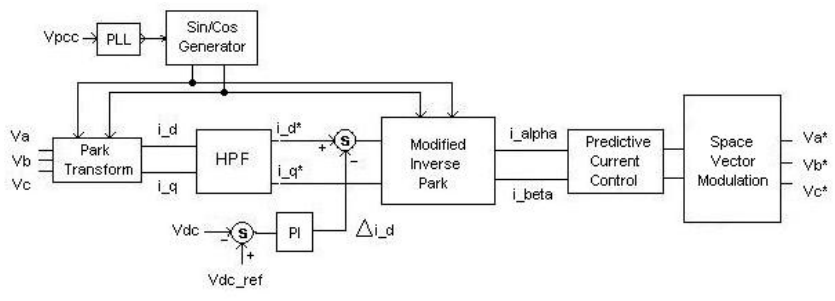

Figure 5. New Control Implementation

Note that the controller in [5] is designed to control an AC machine. This paper modifies the strategy to allow the controller to control currents which are injected into threephase lines.

This controller outputs the same form of SVM switching as shown in Fig. 4. However, the analysis of this controller 


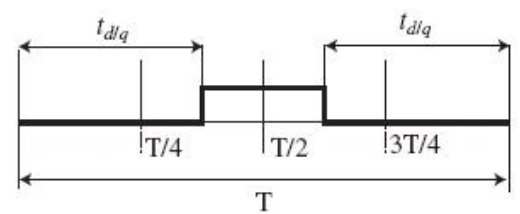

Figure 6. Two-Phase Switching Pattern

is undertaken on a two phase basis. Hence we can define the duty cycle of a two phase waveform, which is depicted in Fig. 6:

$$
\alpha_{d, q}= \pm \frac{T-2 t_{d, q}}{T}
$$

When the voltage waveform shown in Fig. 6 is applied across the output filter inductance, the current in the middle of the control interval is given by:

$$
\begin{aligned}
i[T / 2]-i[0] & =\frac{1}{L}\left(\frac{\alpha[0, T] V T}{2}-\frac{e_{a v}[0, T] T}{2}\right) \\
& =\frac{1}{2}(i[T]-i[0])
\end{aligned}
$$

Where $\alpha$ is the duty cycle, $L$ is the filter inductance, $e_{a v}$ is the average back-emf (in the case of the active filter this will be the average supply voltage at the PCC), $T$ is the control period, $V$ is the magnitude of the applied square wave $\mathrm{d}$ or $\mathrm{q}$ axis voltage and $i$ is the $\mathrm{d}$ or $\mathrm{q}$ axis current.

The result in (8) means that sampling the current in the middle of the control interval gives the same information as sampling at the end of the interval, this result will be used in the following analysis.

Using the basic voltage and current relationship for an inductor we can form the following equation:

$$
i_{a v}[0, T]=\frac{1}{L}\left(\frac{\alpha[0, T] V T}{2}-\frac{e[0] T}{2}\right)+i[0]
$$

Rearranging to compute the duty cycle;

$$
\alpha[0, T]=\frac{1}{V}\left\{\frac{2 L}{T}\left(i_{\text {des }}[0, T]-i[0]\right)+e[0]\right\}
$$

Where $i_{d e s}$ is the desired average current over the control period.

From (10) we can calculate the duty cycle required to produce a desired current. Note that (10) relies on values at the beginning of the control interval, this requires the computations to occur instantaneously at $\mathrm{t}=0$. This is non-causal, therefore the evaluation is undertaken in the previous control interval with predicted values of current for the subsequent interval. A linear approximation is used to estimate these values.

To implement the current control algorithm in a continuous time Saber simulation is relatively straight forward because the calculations are assumed to be instantaneously executed. The algorithm needs modifying and expanding for it to be able to operate within a microcontroller. From [5], the modified equation becomes:

$$
\alpha[k, k+1]=\frac{1}{V}\left\{\frac{2 L}{T}\left(i_{\text {des }}[k, k+1]-i[k]\right)+e[k]\right\}
$$

where:

$$
\begin{aligned}
i[k] & =2 i[k-0.5]-i[k-1] \\
e[k] & =2 e[k-1]-e[k-2]
\end{aligned}
$$

Note that the above equations use a linear approximation for the voltage at the PCC and the desired current in the next control interval. We are using the result from (8) which proved that the current value at the middle of the control interval can be used to infer the current at the end of the control interval. As a consequence of this the computations must be undertaken in the second half of the control interval.

The above theory requires sampling within the microcontroller every half control interval. To achieve this a timer was synchronized with the SVM calculations; every half cycle the timer overflows and causes an interrupt. Thus the interrupt runs twice every control interval, alternating between two algorithms. Mid control interval, the interrupt stores the phase currents and evaluates the control algorithms. At the end of the control interval, the interrupt stores both the phase currents and voltages at the PCC.

It has been shown that given a desired average current an appropriate duty cycle can be applied to produce this current. Therefore the digital current controller algorithm needs only as input a reference current. There is no need for the proportional controller and the $\mathrm{K}$ gain used to form a voltage reference as in [1].

The use of this predictive current control strategy measures and filters the load current, as opposed to [1] which acts on the spectrum associated with the supply current. The load current's harmonics are being directly supplied by the active filter, and hence via KCL, the supply harmonics are reduced. This is a subtle but important difference to the proportional control strategy described previously.

\section{EXPERIMENTAL RESULTS}

This paper presents both Saber simulations and hardware results, recorded on a digital oscilloscope. The software and hardware models conform to the parameters and specifications provided in Table I.

\section{A. Simulation Results}

The system configuration as depicted in Fig. 2 was simulated with both; the control scheme discussed in [1] and the new control scheme implemented in this paper. Fig. 7 shows the supply, load and filter currents when using the predictive current controller. Fig. 8 shows the Fourier spectrum of these signals.

Fig. 7 and 8 show a significant reduction in the Total Harmonic Distortion (THD) of the supply current. The THD in the load is $93.7 \%$, while the THD in the supply, with the active filter operating, is $13.5 \%$.

The DC bus control PI loop was simulated with a proportional gain of two and an integral gain of one.

Fig. 9 and 10 compare the transient response of the control scheme discussed in [1] and that of the new predictive current controller.

The load change in this case consisted of switching an identical second three phase diode rectifier onto the PCC. It can be seen from the graphs that the settling time of the predictive controller is significantly smaller than that of the proportional controller. Therefore, the transient response of the predictive implementation is superior. A superior transient response can 


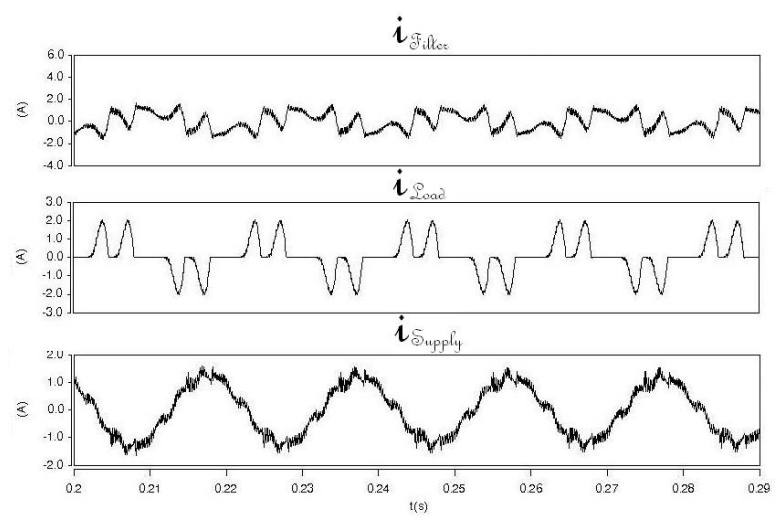

Figure 7. Saber Simulation: Filter, load and supply currents
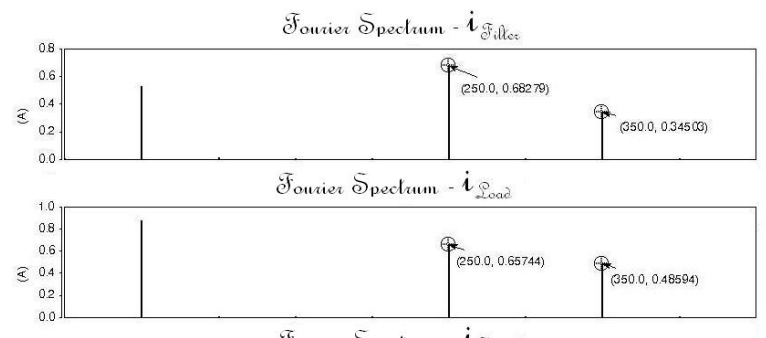

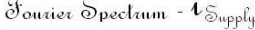

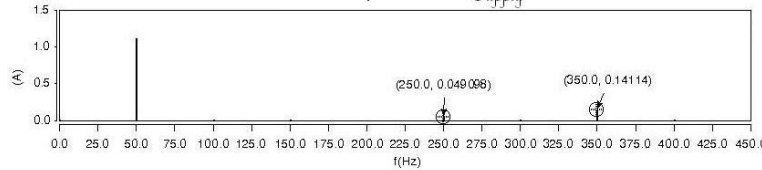

Figure 8. Saber Simulation: Fourier Spectrum of filter, load and supply currents

significantly improve power loss and deleterious effects on electrical equipment caused by increased transient harmonics, considering the frequent switching of today's domestic and industrial loads [6], [7].

When the current control algorithms are implemented digitally within a microcontroller there will inherently be a control delay. It is useful to investigate how large this delay can be before the output current waveforms are significantly effected. This allows determination of the minimum control frequency for the predictive current control.

Utilising the ideal time delay element in Saber, it was found that introducing a delay of less than $0.1 \mathrm{~ms}$ produced no sig-

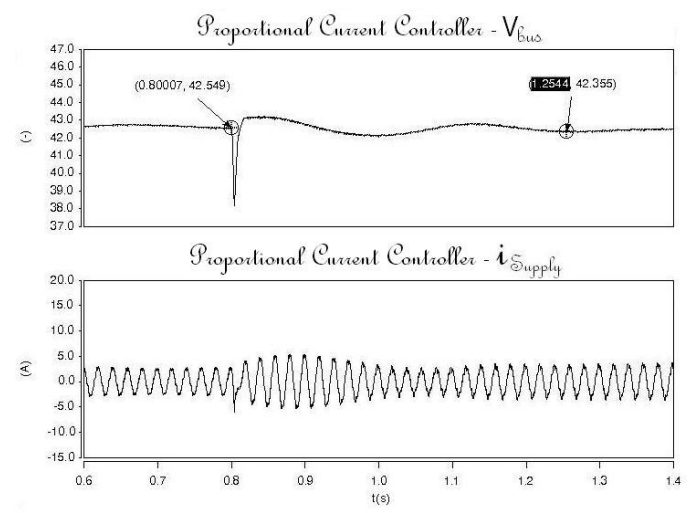

Figure 9. Saber Simulation: Proportional controller's response to load change

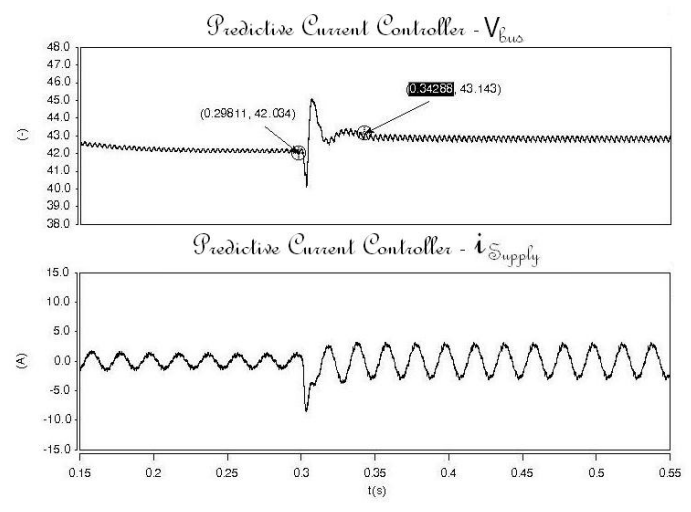

Figure 10. Saber Simulation: The predictive controller's response to load change

nificant deterioration in the controller's ability to compensate. The resultant waveform with a delay of $0.25 \mathrm{~ms}$ is shown in Fig. 11.

Fig. 11 shows an increase in THD of the supply current, as compared to when the delay was insignificant in Fig. 8. The waveforms also show a change in the load current's frequency spectrum. This occurs due to the distortion in the voltage at the PCC. When a non-sinusoidal voltage is supplying the threephase diode rectifier, the load current spectrum will change due to the different turn on and turn off times for the diodes. More significant distortion of the PCC voltage occurs due to additional current harmonics being sunk from the supply into the active filter. These currents arise from the phase difference between the PCC voltage and the voltage produced by the active filter.

The voltages at the PCC and the active filter are two Fourier series. The filter current is equivalent to the PCC Fourier series minus the active filter Fourier series, divided by the filter impedance. Using the linearity of the Fourier series coefficients property, we can calculate each harmonic current separately and sum the components at the end of the calculations. We can define each harmonic PCC and filter voltage phasor as follows:

$$
V_{P C C_{k}} \angle 0^{\circ} \& V_{A F_{k}} \angle \theta
$$

The expression for each harmonic filter current can then be calculated as:

$$
\begin{gathered}
\left|I_{k w_{s}}\right|=\frac{\sqrt{\left(V_{P C C_{k}}-V_{A F_{k}} \cos \theta\right)^{2}+\left(V_{A F} \sin \theta\right)^{2}}}{w_{k s} L} \\
\angle I_{k w_{s}}=\tan ^{-1}\left(\frac{-V_{A F_{k}} \sin \theta}{V_{P C C_{k}}+V_{A F_{k}} \cos \theta}\right)-90^{\circ}
\end{gathered}
$$

Note that when the time delay is zero, $\theta$ is zero and the expressions reduce to:

$$
\begin{gathered}
\left|I_{k w_{s}}\right|=\frac{V_{P C C_{k}}-V_{A F_{k}}}{w_{k s} L} \\
\angle I_{k w_{s}}=-90^{\circ}
\end{gathered}
$$

A comparison of (12) and (14) shows that introducing a delay into the computations has effected the phase of each harmonic filter current. This subsequently changes the phase of the supply current via KCL. The significant distortion of the 
supply current introduces a further amplified distortion in the PCC voltage. Thus the frequency spectrum of the three-phase diode rectifier's current changes.

The increase in THD in the supply current can also be explained with reference to (11), (12), (13) and (14). The out of phase filter current, with reference to the load current, is no longer supplying the load's current harmonics, therefore these harmonics are supplied via the supply, and hence the increase in THD.

Results show that this introduced delay will have a limiting effect on the devices ability to compensate. As the delay approaches $0.25 \mathrm{~ms}$ a significant distortion can be seen in the source current. This correlates to a required control frequency above $4 \mathrm{kHz}$ to achieve satisfactory compensation.
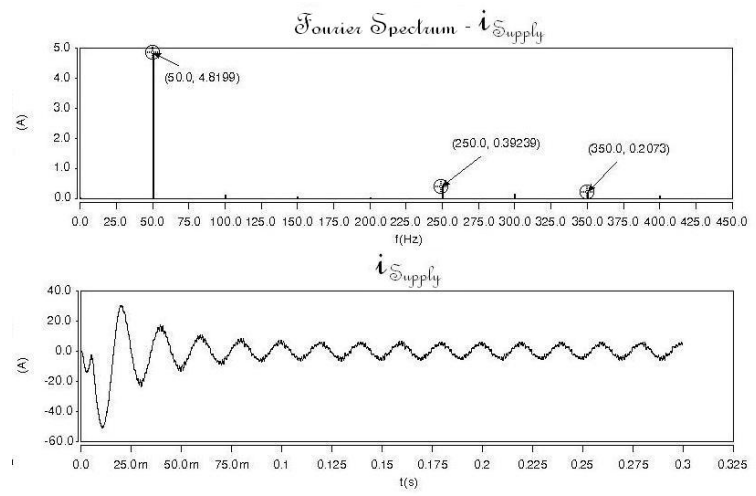

Figure 11. Effect of control system delay

\section{B. Hardware Implementation}

The controller of [1] was successfully implemented using hardware as described in Fig. 2 and Table I. The system was operated utilising the control scheme shown in Fig. 1. A comparison of Fig. 12 with Fig. 13 shows a reduction in power of $6.5 \mathrm{~dB}$ and $4.9 \mathrm{~dB}$ respectively, in the 5 th and 7 th harmonics. These results show the correct operation of the Low Voltage Model.

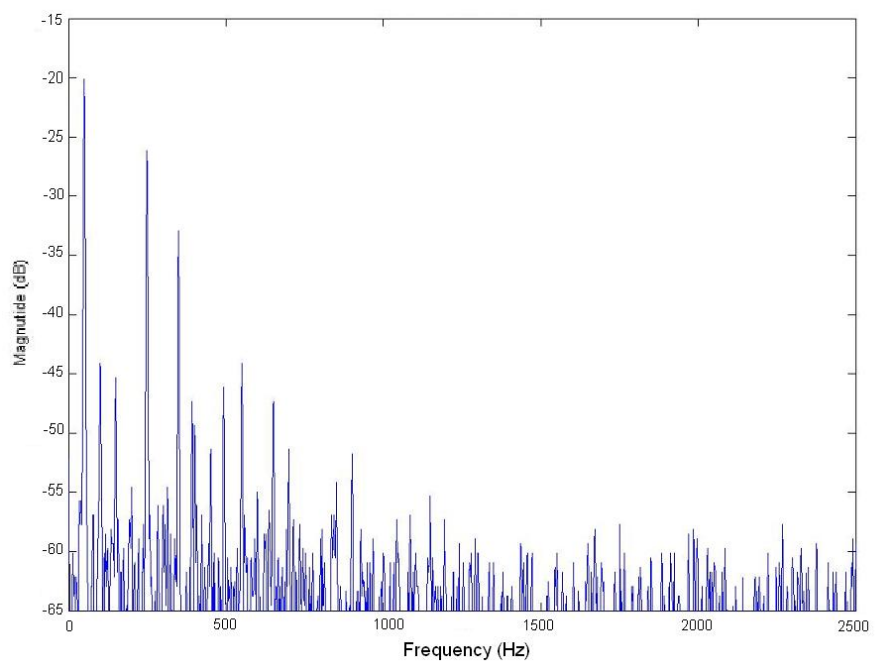

Figure 12. Fourier Spectrum of load current

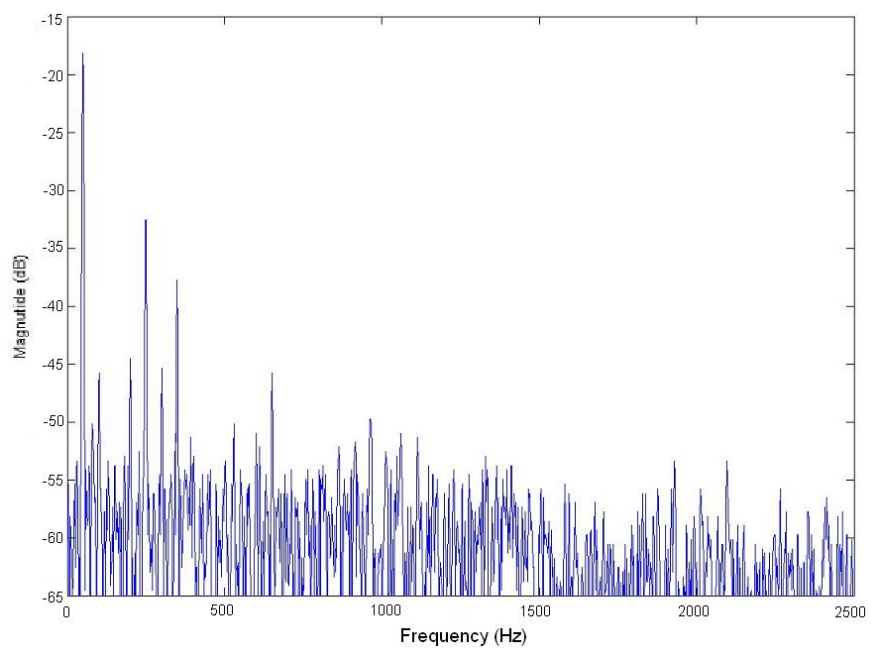

Figure 13. Fourier Spectrum of supply current

\section{CONCLUSIONS}

This paper presented a new implementation of an AHF which attempts to improve the control scheme proposed in [1]. The new implementation removes the output stages of the control scheme; the proportional controller and three single phase triangle wave PWM controllers. The output stage is replaced with a predictive current controller [5] based in the $\alpha \beta$ frame and an SVM generator. The current controller samples the voltage at the PCC and utilises SVM to produce a desired average current by the end of each control period. Thus a change in control will occur, as a response to a variance in load, within one cycle.

Control strategies such as those in [1] and [2] inherently have poor performance for transient suppression of harmonics; due to the delay of the P and PI loops. It can be seen from the experimental results presented in this paper that the settling time of the predictive controller is significantly smaller than that of the proportional controller discussed in [1]. Therefore, the transient response of the predictive implementation is superior. A superior transient response can improve power loss and deleterious effects on electrical equipment caused by increased transient harmonics, considering the frequent switching of today's domestic and industrial loads.

\section{REFERENCES}

[1] H. Akagi, "Active harmonic filters," Proceedings of the IEEE, vol. 93, no. 12, pp. 2128-2141, Dec. 2005.

[2] A. Asiminoaei, C. Lascu, F. Blaabjerg, I. Boldea, "New current control structure for shunt active power filters," IEEE Industry Applications Conference, vol. 1, pp. 183-190, Oct. 2006.

[3] H. Akagi, E. H.Watanabe \& M. Aredes, "Instantaneous power theory and applications to power conditioning," IEEE Press, New Jersey, 2007.

[4] H. Akagi, W. Tangtheerajaroonwong, T. Hatada \& K. Wada, "Design and performance of a transformerless shunt hybrid filter integrated into a three-phase diode rectifier", in IEEE Trans. on Power Elec., vol. 22, no. 5, Sept 2007.

[5] R. E. Betz, B. J. Cook, S. J. Henriksen, "A digital current controller for three phase voltage source inverters," IEEE Conference Record of the Industry Applications Conference, vol. 1, pp. 722-729, Oct. 1997.

[6] R. Dugan, "Electrical power systems quality" - Second Edition, McGrawHill, New York, 2002.

[7] P.C. Bennett, V. Darley, S.M. Abbott, "The effects of harmonic distortion on equipments," IEEE Coloquium on Sources and Effects of Harmonic Distortion in Power Systems, pp. 5/1-5/18, Mar. 1997. 